\title{
Trusting Robots in Teams: Examining the Impacts of Trusting Robots on Team Performance and Satisfaction
}

\author{
Sangseok You \\ HEC Paris \\ you@hec.fr
}

\author{
Lionel P. Robert Jr. \\ University of Michigan \\ lprobert@umich.edu
}

\begin{abstract}
Despite the widespread use of robots in teams, there is still much to learn about what facilitates better performance in these teams working with robots. Although trust has been shown to be a strong predictor of performance in all-human teams, we do not fully know if trust plays the same critical role in teams working with robots. This study examines how to facilitate trust and its importance on the performance of teams working with robots. A 2 (robot identification vs. no robot identification) $\times 2$ (team identification vs. no team identification) between-subjects experiment with 54 teams working with robots was conducted. Results indicate that robot identification increased trust in robots and team identification increased trust in one's teammates. Trust in robots increased team performance while trust in teammates increased satisfaction.
\end{abstract}

\section{Introduction}

Teams are employing robots as collaborative technologies to accomplish dangerous and arduous tasks. For instance, members of construction teams collaborate through their robots to bring down concrete walls safely [54]. First-responder teams save lives by having their members coordinate their actions through robots [33]. These teams have one thing in common, they all have multiple people each with robots to accomplish a team task [66]. These robots can be remote-controlled by humans or be semi or fully autonomous [10,33, 54]. Despite their importance, there is still much to learn with regards to promoting effective teamwork with robots $[46,67]$.

Interaction with and through robots presents an interesting challenge to IS scholars [64]. On one hand, robots can be viewed as any other types of technology. On the other hand, due to their physical embodiment, individuals often humanize robots in ways that can be unique from other technologies [48]. Humanizing robots can lead individuals to interact and react to robots as if they are humans $[45,48,64]$. This humanization of the technology has the potential to fundamentally change our theorizing with regards to the humancomputer interaction $[48,64]$.

Theorizing teamwork with robots begs several interesting questions regarding the relationships between human and their robots. For example, is the relationship between humans and their robots just as important to team outcomes like performance and satisfaction as the relationship between human teammates? If so, what approaches can be used to promote better relationships between humans and their robots? Should we also be concerned with promoting better relationships between humans on these teams? For example, maybe the relationship between human teammates is unimportant and only the relationship with their robot matters. We can also envision a scenario where the opposite might be true. Maybe the relationship between humans and robots is relatively unimportant to team performance and only the relationship between humans is important.

To answer these questions, we turn to theories of trust. Trust is one construct that has consistently shown to be relevant across many settings involving both human-to-human relationships and human-totechnology relationships $[17,49]$. Trust - the belief that another will follow through on your behalf - is an important construct in both the literature on teamwork and technology use [39]. In teams, trust among teammates often predicts various team outcomes, including team performance and job satisfaction [12]. Trust toward a technology has also shown to be an important predictor of use with that technology [34, 61]. In particular, McKnight et al. [39] found that trusting beliefs in a specific technology led to a greater intention to explore and use more features of the technology.

Taken together, the literature on teamwork and technology use seems to suggest that trust may be vital to helping us better understand performance in teams working with robots. In this study, we focus on two trusting relationships: team trust in robots and team trust in humans. Team trust in robots is defined as the team's belief that the robots will meet or follow through on the team's expectations. Team trust in humans is defined as the team's belief that the humans in the team will meet or follow through on the team's expectations. The goal of this study is to determine if team trust in robots and 
team trust in humans lead to more effective teamwork. Accordingly, this study has two objectives:

1) To examine the impact of team trust in robots and team trust in humans on team performance and satisfaction in teams working with robots

2) To examine ways to promote team trust in robots and team trust in humans

To accomplish this, we conducted an experiment examining 54 teams working with robots. The teams consisted of two humans and two robots performing a time task in an experimental setting. This study employed two manipulations to promote team trust in both robots and humans: robot identification (i.e., psychologically identifying oneself with a robot) and team identification (i.e., identifying with one's team and perceiving a team membership). Robot identification was manipulated by having team members assemble their robots. For team identification, team members and their robots were given identical t-shirts and a team name to promote the perception of team identity. This study also examined whether team trust in robots and in humans facilitated team performance and satisfaction. In doing so, this study goes beyond prior research by not only examining these two distinct trusting relationships but also linking them to important team outcomes. Results offer new insights into teamwork with robots.

\section{Theoretical Background}

In this section, we review several bodies of literature that both inform and motivate our research. First, we provide a brief introduction of the trust literature in teamwork. We highlight the benefits of trust in humans. Then, we discuss and present a review of the current IS literature on trust in technology. This includes a discussion of trust in the technology acceptance literature. Finally, we highlight the research on trust in robots from the literature on human-robot interaction.

\subsection{Trust in Teamwork}

Trust has been viewed as a property of interpersonal relationships emerging across wide range of collaborative settings between individuals, between teams, and even between organizations [68]. Trust is one of the most crucial predictors of success in teams [68]. Research shows evidence that trust is positively associated with individual and team performance in many settings [30, 60]. For instance, in collocated work teams, trust among teammates has shown to increase performance and satisfaction $[11,12]$. For example, De Jong and Elfring [12] found that inter-team trust among employees in a multinational consultancy firm increased team performance. The positive effects of trust have also been found in virtual teams [2]. For instance, telemedicine operational teams performed better when teammates had high levels of interpersonal trust [43]. Moreover, Robert [47] found that trust in virtual teams increased team performance; this positive relationship was reduced monitoring of individual behaviors.

Researchers argue that there are benefits of trust in teams because trust promotes collaboration through increased cooperation among individuals [26]. Trust helps individuals deal with the complexity and uncertainty associated with collaborative work [68]. In particular, trusting relationships require less effort to coordinate workload [12]. As the effort needed to coordinate decreases, team members become more willing to engage in cooperative behaviors [56]. Trust among team members leads them to put aside personal interests and focus instead on team goals $[24,60]$. For example, trust has been a strong contributor to team cohesion [25, 44]. Individuals in cohesive teams put more effort to achieve team objectives, which results in better team performance and satisfaction [4, 44]. The explains why trust is linked to positive team outcomes.

\subsection{Trust in Technology}

The concept of trust has been examined for understanding relationships and interactions with various information technology (IT) artifacts [21, 36]. In this research, trust in technology was conceptually distinguished from the conventional notion of trust in prior studies, which mostly focus on interpersonal trust - capturing relationships between people and organizations [58]. For instance, McKnight, Carter, Thatcher, and Clay [39] conceptualized trust in a specific technology as one's belief of functionality, helpfulness, and reliability in the specific technology. Their conceptualization of trust in a specific technology was adapted from aspects of interpersonal trust in teams and organizations, including competence, benevolence, and integrity, derived from the literature of interpersonal trust such as Mayer et al. [38] and McKnight, Cummings, and Chervany [40]. Furthermore, they reported that trust in a specific technology positively predicted an individual's intention to explore and engage in deep-structure use of the technology [39].

However, despite the empirical evidence of trust in technology and the importance of examining trust in specific types of technology, IS researchers have not examined trust in robots. Most studies examining trust in technology were conducted in contexts of traditional information systems including spreadsheet applications [39], e-commerce sites [61], and database systems [34]. For example, Lankton et al. [34] compared human-like trust in technology (i.e. integrity) and system-like trust in technology (i.e. reliability). Therefore, investigating 
trust in robotic systems will contribute to the current literature of trust in technology.

\subsection{Trust in Robots}

Many HRI scholars have argued that because individuals often project human-like traits onto robots, trust in robots should be viewed as a type of interpersonal trust [8, 17]. Recent research has confirmed that the social interactions between humans and robots can lead many humans to develop interpersonal trust in robots in much the same they do with other humans $[20,31]$. The evidence of interpersonal trust in robots have been observed in interactions with various types of robots in varying degrees of its characteristics, such as intelligence and autonomy [32] and appearance [20, 50]. Interpersonal trust is the expectation that someone will act in your best interest [49]. This is somewhat different from trust based on reliability and functional dependability, which is often used to represent trust between humans and technology [13, 62]. Trust in robots includes aspects of both trust in humans and in technology [15, 20, 62].

The literature on trust in robots has several relatively unexplored areas. One, the literature has focused on the role of trust in facilitating interaction with social robots by promoting engagement and enjoyable interactions between an individual and their robot. From this literature, it is clear that humans are much more engaged with and build a stronger relationship with their robot when they trust their robot $[15,16,28]$. Scholars investigating the social robots have ignored the potential impacts of trust on the performance of teams working with robots. Yet, in many cases teams working with robots are assembled to accomplish tasks effectively and as efficiently $[10,27]$. Therefore, understanding the impact on trust on team performance can contribute to our understanding of teamwork with robots.

Two, these studies have only examined the impact on trust between one human and one robot. This is problematic in at least two ways. First, teams working with robots can be composed of multiple humans and robots $[17,63]$. This means that the trust between multiple humans and multiple robots should be considered to better understand teamwork in teams working with robots. Second, in the context of teamwork with robots, trust between humans should also be examined alongside human's trust in robots. Investigating the impact of only trust in robots or trust in humans at best presents an incomplete view and at worst presents an inaccurate view on potential impacts of trust in teams working with robots in predicting team outcomes. Therefore, by examining both the impact of trust in humans and the impact of trust in robots on performance and satisfaction, this study provides new insights to the literature of teams working with robots.

\section{Theory and Hypothesis Development}

In the research model for this paper, we propose two ways to increase team trust in robots and team trust in humans: robot identification and team identification. We also propose in this model that the team trust in robots and humans will result in increases in team performance and satisfaction with teamwork.

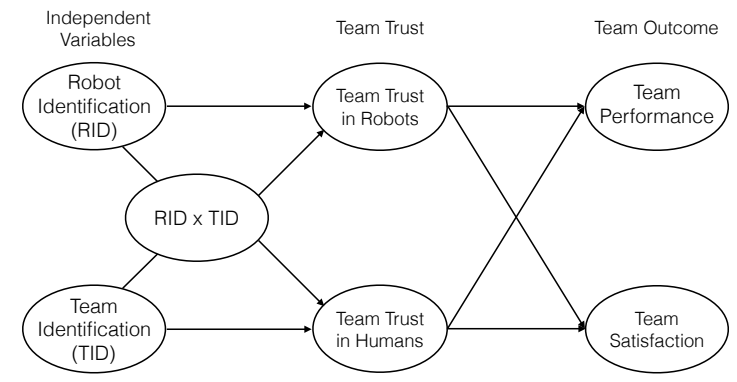

Figure 1 Conceptual Model

Robot identification will increase trust in robots by creating a sense of ownership and identification with the robots $[18,29,41]$. This can be explained by selfextension, which is defined as a phenomenon that individuals extend their self to external objects [5]. People can include physical objects such as technologies and personal possessions into defining their self-identity $[14,57]$. When self-extension occurs, team members can establish a personal bond with a technology by perceiving a special meaning to the object and attaching value and quality related to self $[29,41]$. These bonds and meanings are known to facilitate trust $[22,69]$. We believe that the similar phenomenon can occur for team members in teams working with robots. Research on social robots provide evidence for this assertion. For instance, Groom et al. [18] reported that participants who felt the higher level of self-extension to their robot were more likely to believe that the robot was more honest and trustworthy.

We also suggest that robot identification can increase team trust in humans. The robot identification exercise can induce a perception of shared investment in the team [30]. The fact that both team members are contributing to the team by connecting their self to robots can promote a perception that both members are committed to the team and its success [38]. The belief that one's teammate is committed to the team is positively associated with team trust $[25,60]$.

H1) Robot identification will increase trust in a) robots and b) humans in teams working with robots. 
Team identification should increase team trust in robots and in humans. Team identification is defined as the degree to which team members are psychologically identified with their team [52]. Team identification increases trust by minimizing the perceived differences between teammates and maximizing the perceptions of similarities between them [1, 22]. The similarities become the basis for a shared social identity between teammates [37, 45, 65]. Social categorization and attraction theories tell us that people tend to trust others who they perceive to be similar to them [23, 25]. This explains the strong positive relationship between team identification and team trust [19]. Given that humans tend to project personality and social characteristics onto technology artifacts like robots, it is likely that they would believe their robots were more similar to them when humans were more identified with the team.

H2) Team identification will increase trust in a) robots and b) humans in teams working with robots.

We also posit that there should be interaction effects between robot identification and team identification. When teams working with robots are exposed to both robot identification and team identification, they should have significantly higher levels of trust in both robots and their human teammates than when exposed to either treatment alone. Robot identification and team identification increase trust separately but complementary ways. Robot identification promotes team trust in robots by establishing a personal connection between the humans and their robots and promotes trust in humans by providing them with an opportunity to make a mutual commitment to their team. On the other hand, team identification enhances trust by creating an identity that minimizes perceptions of differences and promotes perceptions of similarities between humans and between humans and robots. When teams have a strong connection with their robots, believe their human teammate is committed, and believe they are similar to both their human teammate and their robots, they should have higher levels of team trust in both their robots and humans.

H3) There is an interaction effect between robot identification and team identification, in such a way that team trust in a) robots and b) humans will be the highest in teams with both robot identification and team identification.

In addition, trust in robots and humans should increase team performance. Team trust in humans has been linked to better team performance $[2,25]$. The performance benefits of trust have often been explained by the heightened engagement and motivation along with the reduction of worry and concern in teams $[12$,
25]. These benefits explain why studies have linked trust in teammates to better team performance $[3,12,68]$.

Researchers have demonstrated that trust in a robot is positively associated with motivation to interact with that robot $[50,53]$. It is also likely that trust in robots should also be associated with increases in confidence in the work being done with the robot. This, in turn, should lead to a reduction in worry and concern and increases in concentration and focus [9]. Humans should perform better with robots when they are more motivated to interact with them, less worried, and more focus while performing tasks with them.

H4) Team trust in a) robots and b) humans will increase team performance.

Furthermore, team satisfaction can be seen as a measure of team members' positive feelings about their team experience [7]. Team trust in all human teams is positively related to satisfaction [25]. Similarly, individuals in teams working with robots are likely to feel higher satisfaction with their team as their level of trust increases in their robots and teammates.

H5) Team trust in a) robots and b) humans will increase team satisfaction.

\section{Method}

To investigate the effects of robot identification and team identification on trust and team effectiveness, we conducted a 2 (robot identification: robot identification vs. no robot identification) $\times 2$ (team identification: team identification vs. no team identification) betweensubjects experiment in a controlled lab environment. Participants were invited to a lab and performed a collaborative task with two robots and another participant. The goal of the task was to deliver five small water bottles from one point to another point by using remote controlled robots as fast as possible.

\subsection{Participants}

There were 108 participants in 54 teams working with robots recruited from a large subject pool at a midwestern university in the United States. The mean age was 24 and 54 were males. Each team working with robots consisted of 2 humans who operated 2 robots. Individuals were randomly assigned to a team. Each team was randomly assigned to one of four treatments: robot identification only, team identification only, robot identification $\times$ team identification, or the control group. There were 13 teams in the robot identification only treatment, 15 teams in the team identification only treatment, 13 teams in the robot identification and team identification treatment, and 13 in the control group. 


\subsection{Robots}

We used robots made of Lego ${ }^{\circledR}$ Mindstorms ${ }^{\circledR}$ EV3. The robots were designed to be able to grab small objects. Infrared remote controllers were used to control the robots. The robots spoke (e.g., "Okay") when loading and unloading the water bottles. The robot indicated directions of movement on its display located on its back. Both robots used for the experiment were identical in forms and technological specifications.

\subsection{Manipulations}

4.3.1. Robot identification. The independent variable robot identification had two levels: robot identification and no robot identification. Manipulation of robot identification was to elicit the perception of selfextension by assembling their own robot. In the robot identification condition, participants were asked to assemble their robot. Each participant assembled their own robot but did so in the same room. The identical bricks and instructions were given to both participants in the team. The instructions included images of each assembling process along with texts. Participants were told that the assembling portion of the study was not a test. They were allowed to take as long as they wanted to complete the assembly task. All participants completed the assembly process.

4.3.2. Team Identification. The manipulation of team identification was done with uniforms and team names. Basketball jerseys with the university's name printed on the front were worn by human teammates, whereas sixmonth infant clothes which also had the university's name printed on the front were used as uniforms for the robots. Participants wore the uniforms while performing the experimental task and put the uniforms on their robots themselves. Along with the uniforms, participants were asked to come up with a unique team name for the team.

4.3.3. Experimental Task. The objective of the task was to deliver five water bottles from point $\mathrm{A}$ to point $\mathrm{C}$ (see Figure 2).

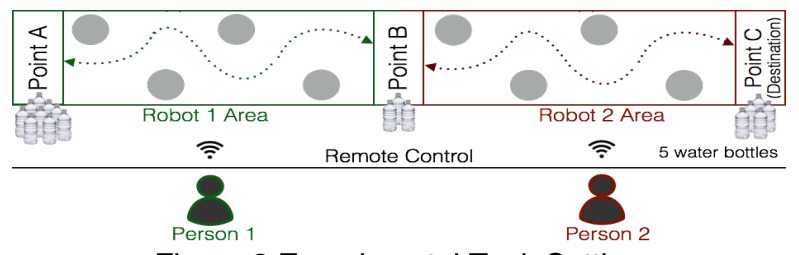

Figure 2 Experimental Task Setting

The first team member used their robot to deliver water bottles from Point A to Point B. The second team member used their robot to deliver the water bottles from Point B to Point C (Final Destination). The task was designed to be interdependent. The first team member was not allowed to deliver water bottles beyond Point B. The second team member could not use their robots to pick up any bottles than were not already at point $B$. This ensured that one team member could not complete the task without the help and cooperation of the other team member. The task was completed once five water bottles had been delivered from point A to point $\mathrm{C}$. Four cones taped to the cardboard area were used as obstacles.

Each team was informed that they were competing with all the other teams for the best time. They were also informed that there would be an additional monetary award for the three best-performing teams in the entire study. The team with the fastest time would receive $\$ 100$ and the second and third place teams would receive an additional $\$ 40$ and $\$ 20$, respectively. This was in addition to the $\$ 20$ participation fee given to all.

Participants were also informed of the 3 rules of the completion. One, only robots were allowed to touch and move water bottles while participants were required to stay outside the work area. Two, robots had to stay inside their designated work area. For example, the first robot was only allowed to move between points $A$ and point $\mathrm{B}$ and the second robot between point $\mathrm{B}$ and $\mathrm{C}$. Three, participants could not swap out robots.

\subsection{Procedure}

The experiment took place in two separate rooms: a treatment room and a task room. The treatment room was used for greeting, briefing, answering questionnaires, and experimental manipulations. The task room was only used for the experimental task.

The experimental procedure began by welcoming participants and providing them with a brief introduction of the study. Participants were then given consent forms. If they consented, they were asked to fill out a short pre-questionnaire on their demographic information. Participants were then provided with both instructions on the experimental task along with instructions about how to operate the remote-controlled robot. Next, a video was shown which went over the same instructions with visual images.

After the video, participants who were assigned to the robot identification condition were given the building instructions and asked to build their robot. Participants who were assigned to team identification treatment were asked to select a uniform and team name. In the robot identification and team identification treatment, participants went through the building activity first and then the team identification treatment. In the control group, team members went directly to the next step below.

The experimenter guided participants to the task room. Participants were asked to turn the robots on. 
Next, participants engaged in two different types of training. First, they were allowed to operate their robots freely for 2 to 3 minutes outside of the work area. Second, they practiced moving 5 water bottles as a team from point $\mathrm{A}$ to point $\mathrm{C}$. They were allowed 2 complete trial runs to simulate the actual timed task. The training was provided to ensure that participants had similar levels of robot control skills before conducting the main task. Afterward, the timed task was conducted. A stopwatch was used to record the time it took participants to deliver the fifth water bottle to Point $\mathrm{C}$. Once the time tasked was completed, participants were given their time. Typically, the entire task from initial training to the timed run took between 25 and 30 minutes.

When participants were finished with the task, they were guided to the treatment room to complete a postquestionnaire. The experimenter then debriefed, thanked, paid, and dismissed the participants.

\subsection{Measures}

4.5.1. Interpersonal Trust in Robots and Human Teammate. Interpersonal trust was measured as a network construct. Both team members rated their level of trust in both robots and their human teammate. The items they used to rate their teammate and the two robots were taken from $[25,38]$. An example item was "I really wish I had a good way to oversee the work of this team member on the task". The scale was measured using a 5-point Likert and was reliable, 0.87.

To calculate the team trust in robots, each team member's rating of both robots were averaged. Next, both team members' scores were averaged together to create a team level measure of trust in robots. The procedure to calculate the measure of team trust in human teammates was similar. The two individual ratings toward each other were averaged to create the team trust in human teammates. In order to aggregate the individual measurement to the team level, we calculated intra-class correlation coefficient (ICC(1)). According to Bliese [6], values greater than 0.1 justifies aggregation. ICC(1) for trust in robots were 0.26 and 0.29 for trust in teammate, both of which justifies aggregation to the team level.

4.5.2. Team Performance. Task duration (in seconds) was used as team performance. The task was completed once the fifth water bottle was delivered to Point $\mathrm{C}$.

4.5.3. Satisfaction with Teamwork. Team satisfaction was measured using 3 items adapted from [7] based on 5-point Likert scale. Items included "Looking back I was pleased with how we complete the team task". The scale reliability was 0.93 . ICC(1) for satisfaction with teamwork was 0.8 .
4.5.4. Disposition to Trust. Disposition to trust was included as a control variable. Prior studies have found that individuals differ significantly when it comes to their propensity to trust [49]. Disposition to trust was measured with 6 items that measured an individual's general predisposition to trust [49]. The items were adopted from [51] and measured using a 5-point Likert scale. Items included "Many people are honest in describing their experience and abilities". The scale reliability was 0.74 and the $\operatorname{ICC}(1)$ was 0.25 .

\section{Results}

We also tested Negative Attitudes Toward Robots (NARS) scale [42], participants' gender, age, and previous knowledge on computer, robotics, and Mindstorms ${ }^{\circledR}$ as covariates in the analysis based on prior studies [55]. None of these variables had significant effects on the results and were excluded.

\subsection{Trust in Robots and Human Teammate}

H1 through $\mathrm{H} 4$ were tested using ANCOVA. H1, posited the main effects of robot identification on trust, was tested. The result showed that trust in robot was significantly higher in teams that built their robots, $M=$ $2.76, S E=0.13$, than teams who did not, $M=2.42, S E$ $=0.13, F(1,51)=4.07, p<0.05, \eta p^{2}=0.07$. Therefore, H1a was supported. However, trust in humans was not significantly different between the teams in the robot identification condition, $M=3.81, S E=0.11$, and those that were not, $M=3.79, S E=0.11, F(1,51)=0.13, p=$ $0.72, \eta p^{2}=0.002$. H1b was not supported (Figure 3 ).

$\mathrm{H} 2$ proposed the main effects of team identification. $\mathrm{H} 2 \mathrm{a}$ posited that identification will increase team trust in robots. There was no significant difference in team trust in robots between teams in the team identification treatment, $M=2.68, S E=0.12$, and those that were not, $M=2.49, S E=0.13, F(1,51)=1.12, p=0.29$. H2a was not supported. $\mathrm{H} 2 \mathrm{~b}$ posited that team identification will increase trust in humans. Teams in the team identification treatment had a significantly higher level of trust in humans, $M=3.98, S E=0.11$, than those teams that were not, $M=3.61, S E=0.11, F(1,51)=5.64, p<$ $0.05, \eta p^{2}=0.10$. H2b was supported (Figure 3 ).

$\mathrm{H} 3$ proposed that there will be an interaction effect between robot identification and team identification on trust in robots and in humans. More specifically, H3a, that there would be an interaction effect on team trust in robots, was supported. A statistically significant interaction effect between robot identification and team identification, $\mathrm{F}(1,50)=5.06, \mathrm{p}<0.05, \eta \mathrm{p} 2=0.09$, on team trust in robots. A post-hoc analysis using Student's $\mathrm{t}$ showed that trust in robots were highest in teams, $\mathrm{p}<$ 0.05, with both robot identification and team 
identification. All other comparisons were not significant. $\mathrm{H} 3 \mathrm{~b}$, the interaction effect on team trust in humans, was also tested. The interaction between robot identification and team identification was not statistically significant, $F(1,50)=0.54, p=0.47, \eta p^{2}=$ 0.01 . Therefore, H3b was not supported.
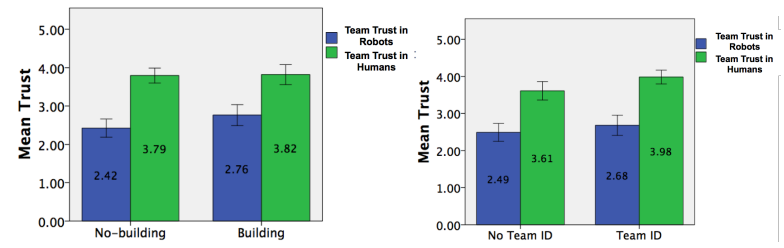

Figure 3 Results for H1a-b (Left) and H2a-b (Right)

\subsection{Trust on Performance and Satisfaction}

H4 and H5 were tested using regression controlling for disposition to trust. $\mathrm{H} 4 \mathrm{a}$, which stated that team trust in robots would increase performance, was supported. Team trust in robots was a significant predictor of performance, $\beta=-0.27, p<0.05$. Disposition to trust was not a significant predictor, $\beta=-0.039, p=0.78$. However, H4b, which stated that team trust in humans would increase performance, was not supported, $\beta=$ $0.23, p>0.11$. Thus, H4b was not supported.

H5 generally proposed that team trust in robots and in humans would increase satisfaction. H5a posited that team trust in robots would be related to increases in satisfaction. H5a was not supported $(\beta=0.20, p=0.15)$. On the other hand, results showed that there was a positive relationship between team trust in humans and satisfaction $(\beta=0.34, p<0.05)$. Therefore, H5b was supported. There was no effect of disposition to trust. The model fit was $r^{2}=0.16$. The summary of the results of the hypotheses is listed below (Table 1).

\begin{tabular}{|c|l|c|}
\hline H1a & Robot-building $\rightarrow$ Team Trust in Robots & Yes \\
\hline H1b & Robot-building $\rightarrow$ Team Trust in humans & No \\
\hline H2a & Team Identification $\rightarrow$ Team Trust in Robots & No \\
\hline H2b & Team Identification $\rightarrow$ Team Trust in humans & Yes \\
\hline H3a & Interaction effect $\rightarrow$ Team Trust in Robots & Yes \\
\hline H3b & Interaction effect $\rightarrow$ Team Trust in humans & No \\
\hline H4a & Team Trust in Robots $\rightarrow$ Performance & Yes \\
\hline H4b & Team Trust in humans $\rightarrow$ Performance & No \\
\hline H5a & Team Trust in Robots $\rightarrow$ Satisfaction & No \\
\hline H5b & Team Trust in humans $\rightarrow$ Satisfaction & Yes \\
\hline
\end{tabular}

Table 1 Summary of Results

\section{Discussion}

The objective of this study was to better understand how to promote team trust in robots and in humans as well as to examine their implications. Results indicated that team trust in robots was important for better performance while trust in humans was not. Team trust in humans was important for satisfaction while team trust in robots was not. Taken together, this study suggests that to better understand teams working with robots, one should consider both the relationships between humans and between humans and their robots.

This study has several contributions. First, results indicated that team trust in robots increased performance but not team trust in humans. There are several ways to interpret this finding. One way is to conclude that team trust in robots is more important to team performance than team trust in humans. However, we caution against over-generalizing from one study.

Another way to view the results is that trust in robots maybe at least as important as trust in teammates to explaining team performance. This implies that trust in robots is an essential element to facilitating performance in teams working with robots [59]. However, the impact of trust in robots and teammates may vary by the context and task [20, 35]. For example, in high-risk work environments like military and rescue operations, trust between teammates may be more important to the performance of teams working with robots [17]. Future studies should be conducted to identify potential moderators of the relationship between trust in robots, trust in teammates, and team performance.

It should also be noted that we examined a specific type of trust: interpersonal trust between humans and robots. We found meaningful impacts on team performance. In doing so, this study supports previous views that humans can view robots more like teammates rather than automated systems and that this relationship can be leveraged to improve teamwork [17, 48]. However, we should be cautious about generalizing our results. For example, our trust measure captured only one specific type of trust. Future studies can compare different types of interpersonal and technology-specific trust to understand which better predicts team outcomes.

Second, results of our study show that only trust in one's teammate increased satisfaction with the team. Trust in robots did not lead to a more a satisfying team experience. This seems to imply that participants could clearly differentiate between the two trusting relationships. One leads to better performance and the other leads to a better team experience. This could be explained by the fact that unlike robots, their human teammates could reciprocate feelings of trust back when fulfilling team task involving robots. This reciprocation may explain why trust in humans can increase satisfaction while trust in robots did not. If so, it would be important to conduct future studies with robots that had the ability to at least simulate reciprocal feelings.

Lastly, this study discovered that different mechanisms may be needed to facilitate team trust in humans and trust between humans and their robots. For 
example, in this study, robot identification increased trust in robots but not trust between teammates. Team identification alone increased trust between teammates but not toward robots. Team identification only increased trust in robots only when combined with robot identification. When you consider the potential time and cost associated with employing multiple mechanisms to promote each one separately, identifying strong mechanisms that promote both is likely to save money and time. Although we found some overlap between the factors that facilitate trust in robots and trust in teammates, more research is needed to fully identify factors that can achieve both. Taken together, this study asserts that trust is important to the success of teams working with robots and that promoting trust should be approached by distinguishing the promotion of team trust in robots versus trust in humans.

The present study has several limitations. First, we examined one type of robot. For example, there are robots with varying degrees of autonomy and intelligence. Second, we examined one particular type of task. There are many other types of task more or less interdependent and more or less complex than others. Finally, like all experimental studies this study was conducted in a controlled setting. Results of this study could be complemented with additional field studies.

\section{Conclusion}

Results of our study demonstrate that we can enhance team performance in teams working with robots by promoting team trust in robots and enhance satisfaction by promoting team trust in humans.

\section{References}

[1] Abrams, D., and M.A. Hogg, "Social identification, selfcategorization and social influence", European review of social psychology 1(1), 1990, pp. 195-228.

[2] Altschuller, S., and R. Benbunan-Fich, "Trust, Performance, and the Communication Process in Ad Hoc Decision-Making Virtual Teams", Journal of ComputerMediated Communication 16(1), 2010, pp. 27-47.

[3] Avolio, B.J., D.I. Jung, W. Murry, and N. Sivasbramaniam, "Building highly developed teams: Focusing on shared leadership process, efficacy, trust, and performance.", 1996.

[4] Beal, D.J., R.R. Cohen, M.J. Burke, and C.L. McLendon, "Cohesion and performance in groups: a meta-analytic clarification of construct relations.", Journal of applied psychology 88(6), 2003, pp. 989.

[5] Belk, R.W., "Possessions and the extended self", Journal of consumer research 15(2), 1988, pp. 139-168.
[6] Bliese, P.D., "Within-group agreement, nonindependence, and reliability: Implications for data aggregation and analysis.", 2000.

[7] Briggs, R.O., G. de Vreede, and B.A. Reinig, "A theory and measurement of meeting satisfaction", System Sciences, 2003. Proceedings of the 36th Annual Hawaii International Conference on, IEEE (2003), 8-pp.

[8] Bruemmer, D., D. Few, M. Goodrich, et al., "How to trust robots further than we can throw them", CHI'04 Extended Abstracts on Human Factors in Computing Systems, ACM (2004), 1576-1577.

[9] Burton-Jones, A., and D.W. Straub Jr, "Reconceptualizing system usage: An approach and empirical test", Information systems research 17(3), 2006, pp. 228-246.

[10] Carpenter, J., "The Quiet Professional: An investigation of US military Explosive Ordnance Disposal personnel interactions with everyday field robots", 2013.

https://digital.lib.washington.edu/researchworks/handle/1773 $/ 24197$

[11] Costa, A.C., K. Bijlsma-Frankema, and B. de Jong, "The role of social capital on trust development and dynamics: implications for cooperation, monitoring and team performance", Social Science Information 48(2), 2009, pp. $199-228$

[12] De Jong, B.A., and T. Elfring, "How does trust affect the performance of ongoing teams? The mediating role of reflexivity, monitoring, and effort", Academy of Management Journal 53(3), 2010, pp. 535-549.

[13] Desai, M., M. Medvedev, M. Vázquez, et al., "Effects of Changing Reliability on Trust of Robot Systems",

Proceedings of the Seventh Annual ACM/IEEE International Conference on Human-Robot Interaction, ACM (2012), 7380 .

[14] Dittmar, H., "Material and consumer identities", In Handbook of identity theory and research. Springer, 2011, 745-769.

[15] Gaudiello, I., E. Zibetti, S. Lefort, M. Chetouani, and S. Ivaldi, "Trust as indicator of robot functional and social acceptance. An experimental study on user conformation to iCub answers", Computers in Human Behavior 61, 2016, pp. 633-655.

[16] Graaf, M.M.A., Living with robots: investigating the user acceptance of social robots in domestic environments, Universiteit Twente, 2015.

[17] Groom, V., and C. Nass, "Can robots be teammates?: Benchmarks in human-robot teams", Interaction Studies 8(3), 2007, pp. 483-500.

[18] Groom, V., L. Takayama, P. Ochi, and C. Nass, "I am my robot: the impact of robot-building and robot form on operators", Human-Robot Interaction (HRI), 2009 4th ACM/IEEE International Conference on, IEEE (2009), 3136. 
[19] Han, G., and P.D. Harms, "Team identification, trust and conflict: a mediation model", International Journal of conflict management 21(1), 2010, pp. 20-43.

[20] Hancock, P.A., D.R. Billings, K.E. Schaefer, J.Y. Chen, E.J. De Visser, and R. Parasuraman, "A meta-analysis of factors affecting trust in human-robot interaction", Human Factors: The Journal of the Human Factors and Ergonomics Society 53(5), 2011, pp. 517-527.

[21] Hoffman, R.R., J.D. Lee, D.D. Woods, N. Shadbolt, J. Miller, and J.M. Bradshaw, "The dynamics of trust in cyberdomains”, IEEE Intelligent Systems(6), 2009, pp. 5-11.

[22] Hogg, M.A., "Social identity and the group context of trust: Managing risk and building trust through belonging", Trust in cooperative risk management: uncertainty and scepticism in the public mind, 2007, pp. 51-72.

[23] Hogg, M.A., and J.C. Turner, "Interpersonal attraction, social identification and psychological group formation", European Journal of Social Psychology 15(1), 1985, pp. 5166.

[24] Hung, Y.-T., A.R. Dennis, and L.P. Robert, "Trust in virtual teams: Towards an integrative model of trust formation", System Sciences, 2004. Proceedings of the 37th Annual Hawaii International Conference on, IEEE (2004), 11-pp.

[25] Jarvenpaa, S.L., T.R. Shaw, and D.S. Staples, "Toward contextualized theories of trust: The role of trust in global virtual teams", Information systems research 15(3), 2004, pp. 250-267.

[26] Jones, G.R., and J.M. George, "The experience and evolution of trust: Implications for cooperation and teamwork", Academy of management review 23(3), 1998, pp. 531-546.

[27] Jones, H., and P. Hinds, "Extreme work teams: using swat teams as a model for coordinating distributed robots", Proceedings of the 2002 ACM conference on Computer supported cooperative work, ACM (2002), 372-381.

[28] Kidd, C.D., "Sociable robots: The role of presence and task in human-robot interaction”, 2003.

[29] Kiesler, T., and S. Kiesler, "My pet rock and me: An experimental exploration of the self extension concept", Human-Computer Interaction Institute, 2004, pp. 85.

[30] Korsgaard, M.A., D.M. Schweiger, and H.J. Sapienza, "Building commitment, attachment, and trust in strategic decision-making teams: The role of procedural justice", Academy of Management Journal 38(1), 1995, pp. 60-84.

[31] Krämer, N.C., A. von der Pütten, and S. Eimler, "Human-Agent and Human-Robot Interaction Theory: Similarities to and Differences from Human-Human Interaction", In Human-Computer Interaction: The Agency Perspective. Springer, 2012, 215-240.
[32] Kruijff, G.-J.M., "Trusting in Human-Robot Teams Given Asymmetric Agency and Social Sentience.", AAAI Spring Symposium: Trust and Autonomous Systems, (2013).

[33] Kruijff-Korbayová, I., "Human-robot disaster response team successfully deployed robots in earthquake damaged monuments | Robohub", 2013. http://robohub.org/humanrobot-disaster-response-team-successfully-deployed-robotsin-earthquake-damaged-monuments/

[34] Lankton, N., D.H. McKnight, and J.B. Thatcher, "Incorporating trust-in-technology into Expectation Disconfirmation Theory", The Journal of Strategic Information Systems 23(2), 2014, pp. 128-145.

[35] Lee, J.D., and K.A. See, "Trust in automation: Designing for appropriate reliance", Human Factors: The Journal of the Human Factors and Ergonomics Society 46(1), 2004, pp. 50-80.

[36] Li, X., T.J. Hess, and J.S. Valacich, "Why do we trust new technology? A study of initial trust formation with organizational information systems", The Journal of Strategic Information Systems 17(1), 2008, pp. 39-71.

[37] Ljungblad, S., J. Kotrbova, M. Jacobsson, H. Cramer, and K. Niechwiadowicz, "Hospital robot at work: something alien or an intelligent colleague?", Proceedings of the ACM 2012 conference on Computer Supported Cooperative Work, ACM (2012), 177-186.

[38] Mayer, R.C., J.H. Davis, and F.D. Schoorman, “An integrative model of organizational trust", Academy of management review 20(3), 1995, pp. 709-734.

[39] Mcknight, D.H., M. Carter, J.B. Thatcher, and P.F. Clay, "Trust in a specific technology: An investigation of its components and measures", ACM Transactions on Management Information Systems (TMIS) 2(2), 2011, pp. 12.

[40] McKnight, D.H., L.L. Cummings, and N.L. Chervany, "Initial trust formation in new organizational relationships", Academy of management review 23(3), 1998, pp. 473-490.

[41] Mugge, R., J.P. Schoormans, and H.N. Schifferstein, "Emotional bonding with personalised products", Journal of Engineering Design 20(5), 2009, pp. 467-476.

[42] Nomura, T., T. Kanda, and T. Suzuki, "Experimental investigation into influence of negative attitudes toward robots on human-robot interaction", Ai \& Society 20(2), 2006, pp. 138-150.

[43] Paul, D.L., and R.R. McDaniel Jr, "A field study of the effect of interpersonal trust on virtual collaborative relationship performance", Mis Quarterly, 2004, pp. 183227.

[44] Powell, A., G. Piccoli, and B. Ives, "Virtual teams: a review of current literature and directions for future research", ACM Sigmis Database 35(1), 2004, pp. 6-36.

[45] Rae, I., L. Takayama, and B. Mutlu, "One of the gang: supporting in-group behavior for embodied mediated communication", Proceedings of the SIGCHI Conference on 
Human Factors in Computing Systems, ACM (2012), 30913100 .

[46] Robert, L. P. (2018). Personality in the Human Robot Interaction Literature: A Review and Brief Critique,

Proceedings of the 24th Americas Conference on Information Systems, Aug 16-18, New Orleans.

http://aisel.aisnet.org/amcis2018/DataScience/Presentations/2 4/

[47] Robert, L.P., "Monitoring and Trust in Virtual Teams", Proceedings of the 19th ACM Conference on ComputerSupported Cooperative Work \& Social Computing, ACM (2016), 245-259.

[48] Robert, L.P., "The Growing Problem of Humanizing Robots", International Robotics \& Automation Journal (IRAJ) 3(1), 2017.

[49] Robert, L.P., A.R. Denis, and Y.-T.C. Hung, "Individual swift trust and knowledge-based trust in face-to-face and virtual team members", Journal of Management Information Systems 26(2), 2009, pp. 241-279.

[50] Schaefer, K.E., T.L. Sanders, R.E. Yordon, D.R. Billings, and P.A. Hancock, "Classification of robot form: factors predicting perceived trustworthiness", Proceedings of the Human Factors and Ergonomics Society Annual Meeting, SAGE Publications (2012), 1548-1552.

[51] Schoorman, F.D., R.C. Mayer, and J.H. Davis, "Empowerment in veterinary clinics: The role of trust in delegation", 11th annual meeting of the Society for Industrial and Organizational Psychology, San Diego, CA, (1996).

[52] Scott, C.R., "Identification with multiple targets in a geographically dispersed organization", Management Communication Quarterly 10(4), 1997, pp. 491-522.

[53] Shah, J., J. Wiken, B. Williams, and C. Breazeal, "Improved Human-robot Team Performance Using Chaski, a Human-inspired Plan Execution System", Proceedings of the 6th International Conference on Human-robot Interaction, ACM (2011), 29-36.

[54] Sullivan, C.C., and A. Sullivan, "Robots, drones, and printed buildings: The promise of automated construction", Building Design + Construction, 2014.

https://www.bdenetwork.com/robots-drones-and-printedbuildings-promise-automated-construction

[55] Takayama, L., V. Groom, and C. Nass, "I'm sorry, Dave: i'm afraid i won't do that: social aspects of humanagent conflict", Proceedings of the SIGCHI Conference on Human Factors in Computing Systems, ACM (2009), 20992108.

[56] Teasley, S., L. Covi, M.S. Krishnan, and J.S. Olson, "How does radical collocation help a team succeed?", Proceedings of the 2000 ACM conference on Computer supported cooperative work, ACM (2000), 339-346.

[57] Tian, K., and R.W. Belk, "Extended self and possessions in the workplace", Journal of consumer research 32(2), 2005, pp. 297-310.
[58] Vance, A., C. Elie-Dit-Cosaque, and D.W. Straub, "Examining trust in information technology artifacts: the effects of system quality and culture", Journal of Management Information Systems 24(4), 2008, pp. 73-100.

[59] de Visser, E., and R. Parasuraman, “Adaptive aiding of human-robot teaming effects of imperfect automation on performance, trust, and workload", Journal of Cognitive Engineering and Decision Making 5(2), 2011, pp. 209-231.

[60] Wieselquist, J., C.E. Rusbult, C.A. Foster, and C.R. Agnew, "Commitment, pro-relationship behavior, and trust in close relationships.", Journal of personality and social psychology 77(5), 1999, pp. 942.

[61] Wu, K., Y. Zhao, Q. Zhu, X. Tan, and H. Zheng, “A meta-analysis of the impact of trust on technology acceptance model: Investigation of moderating influence of subject and context type", International Journal of Information Management 31(6), 2011, pp. 572-581.

[62] Yagoda, R.E., and D.J. Gillan, "You want me to trust a ROBOT? The development of a human-robot interaction trust scale", International Journal of Social Robotics 4(3), 2012, pp. 235-248.

[63] Yanco, H.A., and J.L. Drury, "Classifying human-robot interaction: an updated taxonomy.", SMC (3), (2004), 28412846.

[64] You, S., and L.P. Robert Jr, "Emotional Attachment, Performance, and Viability in Teams Collaborating with Embodied Physical Action (EPA) Robots", Journal of the Association for Information Systems 19(5), 2018, pp. 377407.

[65] You, S., and L.P. Robert Jr, "Human-Robot Similarity and Willingness to Work with a Robotic Co-Worker", Proceedings of the 2018 ACM/IEEE International Conference on Human-Robot Interaction, ACM (2018), 251260.

[66] You, S., and L.P. Robert, "Curiosity vs. Control: Impacts of Training on Performance of Teams Working with Robots", Proceedings of the 19th ACM Conference on Computer Supported Cooperative Work and Social Computing Companion, ACM (2016), 449-452.

[67] You, S., and L.P. Robert, “Teaming Up with Robots: An IMOI (Inputs-Mediators-Outputs-Inputs) Framework of Human-Robot Teamwork", International Journal of Robotic Engineering 2(003), 2017.

[68] Zaheer, A., B. McEvily, and V. Perrone, "Does trust matter? Exploring the effects of interorganizational and interpersonal trust on performance", Organization science 9(2), 1998, pp. 141-159.

[69] Zhang, Y., and C. Huxham, "Identity Construction and Trust Building in Developing International Collaborations", The Journal of Applied Behavioral Science 45(2), 2009, pp. 186-211. 